Sir Paul Collier

\title{
Achieving Socio-Economic Convergence in Europe
}

Europe faces common threats, both geopolitical and environmental, for which it will need common action. But common action, which usually involves sacrificing shortterm national advantage, is politically very demanding. While the impetus may be common threats, sustaining it will only be feasible if the Union has strong legitimacy with Europe's citizens. As Brexit and the rise of European populism has revealed, such practical legitimacy is under attack. In this article, I diagnose the origins of populism and propose ways the Commission can best restore support among those most disaffected.

The origins of European populism are two socio-economic divergences that began around 1980 and have been at their most extreme in Britain. One is spatial, the other educational. I discuss these processes more fully in The Future of Capitalism: Facing the New Anxieties. Here, after a brief summary, I focus on how core European policies have affected them and how new approaches by the Commission could potentially restore social convergence. The subsequent section focuses on the past effects of the Union's four flagship economic policies: the internal market, free movement, the euro, and the identity of being European. The article then focuses on healing spatial divergence, suggesting policies that might enable each region of Europe to have at least one major city that is globally competitive and anchors the region's most able young people. Finally, the article focuses on healing educational divergence, suggesting policies that might enable the half of Europe's population that is less cognitively gifted to acquire and retain skills that make them highly productive.

\section{The political economy of social divergence}

Spatial divergence takes three forms. In some countries, notably Britain, France, Portugal and Poland, national metropoles have outpaced provincial cities and towns, some of which have crashed as their core industry has relocated to Asia. The primary driver of this process, which reverses the trend of the previous two centuries, is probably the increasing globalisation of markets, supporting fewer but bigger winning clusters of agglomeration. Within Europe, London is the most striking example

Sir Paul Collier, Oxford University, UK. of this process, with the city becoming the most successful of the world's three leading financial clusters. The second form of spatial divergence is between regions. It is notable that the main secessionist movements in Europe - Catalonia, Scotland, Italian's northern regions and Flanders - have all been the wealthy regions of their countries wishing to escape from the claims of poorer regions. Again, it is most marked in Britain, where indices of regional inequality have risen very substantially. The final spatial divergence is between countries. This has been reflected in incomes, unemployment and migration. Most notably, Germany has benefited from rising incomes, low unemployment and inflows of skilled labour, whereas Italy and Greece have suffered a large decline in income, high unemployment and the emigration of skilled workers.

The educational divergence is between those with good tertiary education on which sophisticated skills are built that have become steadily more valuable, and those with weaker education who had invested in manual skills. The primary driver of this process is probably technological, i.e. the increased complexity of production. Complexity has increased the need for sophisticated skills which require university-built cognitive capabilities, while simultaneously reducing the value of manual skills.

The spatial and educational divergences have become intertwined due to the tendency of the best-educated young people growing up in declining cities, regions and countries to migrate to the metropoles. We can conceptualise this process as a rise in the productivity of skilled workers in the metropole: an increase in the 'rents of agglomeration', which accrue partly to those who own land and property, and partly to those with high-value skills. These rents attract migrants from the provinces. But potential job seekers are differentiated both by skill and by housing needs - willingness to accept the bedsit lifestyle. The winners, who gain by relocating, will be those with relatively high skill, but relatively low housing demand. ${ }^{1}$ This is why it is predominantly those young people who are well-educated and still single, for whom relocation to

(C) The Author(s) 2020. Open Access: This article is distributed under the terms of the Creative Commons Attribution 4.0 International License (https://creativecommons.org/licenses/by/4.0/).

Open Access funding provided by ZBW - Leibniz Information Centre for Economics.

1 P. Collier, A.S. Venables: Who Gets the Urban Surplus, in: Journa of Economic Geography, Vol. 18, No. 3, 2018, pp. 523-538. 
the metropole is attractive. Once people are married with children, and therefore have a greater need for housing, the gains from higher metropolitan productivity are more than offset by the higher costs of housing. The exit of the brightest and best youth, while their parents are left behind - both physically and perhaps psychologically - aggravates the sense of despair in left-behind places. At its extreme, in provincial America, it manifests as 'deaths of despair'. ${ }^{2}$ Hence, the divergence of the provinces cannot simply be addressed by compensating transfers of consumption. What is needed are credible prospects of recovered pride that retain each region's youth.

These post-1980 spatial and educational divergences interacted with reconfigurations of identity. By 1980, the governments of Western Europe had built welfare states that were without historical precedent. The political underpinnings of this extraordinary achievement were that the terrible experiences of the Second World War, in which civilians had suffered alongside soldiers, had forged a sense of common national solidarity. In consequence, the successful accepted burdensome new responsibilities towards the less successful. For example, in Britain the high-income groups accepted rates of marginal income tax above $80 \%$ in order to fund the National Health Service. Similarly, in France during the Trente Glorieuses, huge state expenditures funded by taxation and debt put in place the transport infrastructure that enabled prosperity to be spatially widely spread.

The new economic divergences gradually undermined this new sense of shared identity. Diverging incomes generated diverging collective identities which gradually unwound the capacity for a sense of common purpose. As income differences widened, successful people in successful metropolises found that their self-interest was to reduce their attachment to their national identity, substituting it for a professional, or metropolitan, identity. Collier presents a simple rational choice model in which, in response to greater income inequality, there is a successful 'peel off' from shared national identity, in which there is a withdrawal from their obligations to less-successful fellow citizens. ${ }^{3}$ An example of this psychological process is the description by a London-based journalist of how he and his fellow metropolitans perceive provincial Britain: "It feels like being shackled to a corpse". ${ }^{4}$

Since well-educated metropolitans have wielded disproportionate political influence, they reshaped policy priori-

2 A. Case, A. Deaton: Deaths of Despair and the Future of Capitalism, forthcoming 2020, Princeton University Press.

3 P. Collier: Diverging Identities: a Model of Class Formation, Oxford Economic Papers, 2019.

4 J. Ganesha: Financial Times, October 2017. ties in favour of their own concerns, which did not include remedying the divergences from which they had benefited. Unsurprisingly, this neglect induced a corresponding shift in the identity of those left behind towards grievance and opposition.

\section{How the flagship policies of the European project affect these divergences}

The European project is primarily political and legal rather than economic, but since the move to the European Union, four flagship policies have each been economically consequential, namely the internal market, free movement, the euro and the promotion of European identity.

\section{The internal market}

The gradual lifting of national barriers protecting markets for goods and services is qualitatively analogous to globalisation: markets become more competitive. This can produce substantial gains, squeezing profits and thereby benefiting consumers, and intensifying the quest for efficiency. As Philippon has shown, the internal market has achieved this, generating substantial benefits. ${ }^{5}$ At a more mundane level, the basic theorems of international trade tell us that liberalisation will produce powerful redistributions within each country. Specifically, the less skill-intensive activities will shift to the low-income countries within Europe, reducing low-skill wages in the countries where they were high, while raising them where they were low. The internal market has therefore helped regional convergence between countries, but accentuated educational divergence within the higher-income countries. Normally, the gains of those who benefit will be larger than the losses of those who become worse off within each country, so that a sufficiently well-designed system of compensation could leave everyone better off.

While the Commission had competencies to enforce mutual trade liberalisation among member countries, it did not have the corresponding competencies to ensure that within each country those who gained would compensate those who lost. This was left to national governments, resulting in considerable variation in policies. Arguably, this matter could have received more attention, and its neglect may have contributed to anti-European sentiment among aggrieved populations of workers in some of the high-income member countries.

5 T. Philippon: The Great Reversal: How America Gave Up on Free Markets, 2019, Belknap Press. 
Free movement

The introduction of free movement affected both spatial and educational divergence. While the basic theorems of economics suggest that the internal market bestowed mutual benefits among member countries, there is no equivalent theorem concerning movements of labour between countries. Once firms and capital become mobile, as they are in Europe, efficiency can be achieved by moving them to labour, rather than labour to firms and capital. Indeed, the central point of the factor price equalization theorem was to show that as long as activities are free to relocate, the internal market should gradually make movements of both labour and capital unnecessary.

The key effect of free movement has been to encourage spatial mobility of labour in the interest of a more efficient allocation of resources for given locations of firms and capital, thereby inadvertently tending to amplify initial spatial inequalities. In practice, those most likely to gain from migration are the skilled, and so it has enabled relocation of the well-educated from the poorer regions of low-income member countries to the richer regions of high-income members. The governments of the poorer countries of Europe that have suffered from rapid brain drain, such as Greece, Estonia and Romania, are now unsurprisingly wary of free movement. In contrast, the German government, which has sought to offset an unsustainably low birth rate through immigration rather than the more costly strategy of greater family support, remains enthusiastic. Free movement has had effects both on the regions of exit and the regions of entry.

As an example of the effects of exit, I take the emigration of around $30 \%$ of Romania's doctors to better paid jobs in Northern Europe. Those doctors who have emigrated have principally come from poor provincial areas of Romania rather than Bucharest, resulting in a severe deterioration in the medical coverage of small towns. The only way for provincial populations to have protected the healthcare of their young and old would have been to raise the incomes of their doctors, already a high-income group in their communities, towards parity with the Northern metropoles. This new outflow of the highly skilled to more attractive opportunities fully meets the efficiency criteria by which resource allocation is commonly assessed. In treating high-income patients in Paris, rather than low-income patients in small-town Romania, the productivity of Romanian doctors as measured by their earnings has unambiguously risen. If efficiency is the sole criterion, then the integration of the internal market has achieved its purpose. It can also be judged to be a success on the Libertarian criterion: Romanian doctors have benefited from the increase in their individual liberty achieved by European cooperation. However, on social well-being criteria, it can be seen as inadvertently damaging: tempting vital members of communities into abandoning their obligations.

As an example of the effects of entry, I take London, the European city that has attracted the most immigrants. Well over half its population is now first- or second-generation immigrant. As discussed, the people who will find relocation to London most attractive will be those with high skills and low housing demand. Prior to free movement, the eligible pool of potential workers from whom these best-suited people were drawn was the 50 million people living in provincial Britain. Free movement radically expanded this pool of eligible people from 50 million to 500 million. One consequence of this more intense competition for jobs in London was that the average skill level of entrants to the London job market rose. This was a gain in allocative efficiency, but as with Romanian doctors, it produced powerful redistributions. The increase in levels of individual skill increased the rents of agglomeration - the gain in productivity from clustering many skilled people together. These rents were shared between those who owned land and property in London and the highly skilled. ${ }^{6}$ But since many British provincial workers who would otherwise have received these jobs had been outcompeted by European workers (with higher skills or lower housing demand), there was a corresponding transfer of these rents of agglomeration. As with Romanian doctors, this can be seen in different ways. It is an increase in allocative efficiency and in freedom for some successful people. But it is also a transfer from provincial Britons. The beneficiaries are London land and property owners, those highly skilled Britons remaining in London, and skilled Europeans who moved to London.

Notably, in these examples, the effects both of exit and of entry disadvantaged the less successful groups of Europe's citizens.

\section{The euro}

The decision to replace national currencies with a common currency left open the rules by which that common currency would be managed. Prior to the common currency, national practices had been very different and so a common currency required some common standard. Had the common currency adopted the practices of the lira, the consequences for spatial divergence would most likely have been quite different from the adoption of the practices of the Deutschmark, which was what actually happened. This gave Germany, with its expectations of

6 P. Collier, A.S. Venables, op. cit. 
low-inflation, a competitive advantage afforded by an undervalued real exchange rate which cumulated to become considerable: hence its rapid growth, very considerable balance of payments surplus and very low unemployment. This advantage was amplified through the Hartz Reforms and the 'black zero', which lowered wage costs that would otherwise have been offset by a market-driven appreciation in the nominal exchange rate. Conversely, Italy, and other previously high-inflation countries, received an initial windfall from reduced interest rates on government debt, generating a temporary boom which delayed downward revisions in wage demands. Subsequently, governments could only maintain payments equilibrium by deflating their economies, hence inflicting high unemployment on their citizens. In response to this divergence in unemployment rates, skilled labour migrated, giving German firms a further windfall from the influx of ready-trained labour. This influx of labour rescued German firms from the consequences of social policies which had induced the birth rate to fall well below replacement rates. But in doing so, it arguably delayed the necessary reforms in social policy.

The divergence due to the euro is now fairly well understood by economists, but not yet sufficiently understood by either citizens or politicians. Notably, in their resistance to a 'transfer union', Germans appear genuinely to be unaware that given the policies adopted for the euro, Europe already is a powerful transfer union of which they have been the major beneficiaries. The modest scale of offsetting fiscal transfers, which is the focus of attention, is trivial in comparison to the effects of real exchange rate misalignment and the relocation of skilled labour. This misunderstanding is important because in a democracy good policy is dependent upon the existence of a critical mass of informed citizens and politicians.

\section{European identity}

The final policy, which indeed was considered so important that it probably motivated the others, was the promotion of European identity. Potentially, such an identity could work either as a substitute or a complement for national identities. The impetus for the founding of the European Community was, understandably, the fear of further intra-European warfare. Just as the purpose of regional economic integration was to create sufficient interdependence in production that such warfare would be materially impossible, the purpose of European identity was initially to substitute for national identity, thereby making intra-European warfare psychologically impossible.

However, the potential for European identity to substitute for national identity has profound consequences for the poorer citizens of Europe's nations. For them, the post-war sense of shared national identity had become a hugely valuable asset. Post-1980, just as the new economic forces of social divergence were necessitating national solidarity, this sense of shared identity was being unwound. The most successful citizens, namely the welleducated metropolitans who have enjoyed rising relative incomes, have gradually peeled off from shared national identity. The option of being 'European' has perhaps been a convenient justification for them to withdraw from obligations to their provincial fellow citizens.

Evidence for this interpretation comes from the structure of support for the European Union. Generally, strongest support for Europe is found among the successful metropolitans, whereas hostility to Europe is most common among the provincial less-educated - the people who have been marginalised by divergence. The clearest evidence of this comes from the voting pattern in the Brexit referendum. The only region of England and Wales to support remaining in the Union was London: every other region voted for Brexit. Further, among the highly educated population, those living in London were more likely to vote for Remain than those outside London, while among the less-educated population, those living in London were even less likely to support Remain that those living elsewhere. ${ }^{7}$ The Brexit Referendum is particularly revealing because it was a rare instance of a vote entirely focused on attitudes toward the Union. However, similar patterns are evident from support for the gilets jaunes in France, the AfD in Germany, the League in Italy, and Vox in Spain.

In essence, to the extent that it has been taken up by citizens to date, the option of European identity has arguably been interpreted primarily not as the acquisition of new obligations towards the less successful regions of Europe, which would evidently help regional convergence, but as the exit from former obligations towards the less successful regions of one's own nation. The Commission might try to address this directly by clarifying that European identity cannot legitimately be used to exit obligations to others within the nation, but incurs further obligations to those in other member countries.

\section{Promoting spatial convergence}

A fundamental rationale for the European project has been to promote spatial convergence. This goal is both valuable and feasible. It is valuable because common European action is increasingly necessary, but the willing-

7 P. Collier: The Future of Capitalism: Facing the New Anxieties, 2018, Allen Lane. 
ness to accept that it should prevail over national preference will dissipate if poorer regions and countries fall behind.

Some market fundamentalists seem to believe that the internal market will automatically achieve regional balance across Europe, and the shift of labour-intensive activities to low-income member countries is indeed a force for convergence. Unfortunately, the spatial allocation of economic activity is more complex than envisaged by the classical theory of international trade: more recent theories emphasise the importance of agglomeration - cities, not countries, are the key spatial unit of analysis. The market responses when the key export base of a city loses competitiveness have recently been analysed by Venables. ${ }^{8}$ Initially, markets drive down the price of property and local wages. The response to these market signals is that the city attracts individual footloose firms whose business models depend upon cheap accommodation and low wages and whose markets are regional or national rather than global. As property gets reoccupied, the scope for a new cluster of knowledge-intensive firms that are globally competitive closes. The city's labour market falls off the escalator of skill accumulation and innovation found only in the clusters of high-productivity firms such as that which was lost.

Successful cities, which are the key spatial phenomena, are the result of coordination: interdependent firms determine investment strategies based on their expectations of how the other firms with whom they need to co-locate will invest. There are an infinite number of these possible spatial equilibria and so firms face radical uncertainty. There are three possible responses to such uncertainty. One is to remain in the current cluster: successful clusters are fairly persistent. The second is indecision: firms preserve the option value of waiting. The third is the emergence of some narrative that circulates within the peer group - the interdependent firms. As the narrative circulates, it gains credence simply because other members of the peer group come to hold the same ideas. It can become a 'conviction narrative' on which firms are willing to rely in taking a decision. ${ }^{9}$ Conviction narratives abound. As Schiller has recently shown, they are often false and eventually implode..$^{10}$ But precisely because there are so many possible spatial equilibria, spatial narratives have the unusual property that over a wide range they can be self-fulfilling.

8 A.J. Venables: Globalization and urban polarization in: Review of International Economics, Vol. 26, No. 5, 2018, pp. 981-996.

9 D. Tuckett, M. Nikolic: The Role of Conviction and Narrative in Decision-Making under Radical Uncertainty, in: Theoretic Psychology, Vol. 27, No. 4, 2017, pp. 501-523.

10 R. Schiller: Narrative Economics: How Stories go Viral and Drive Major Economic Events, 2019, Cambridge University Press.
If Singapore is 'the city of the future', it is considered a safe place in which to invest and so it becomes the city of the future. If Rotherham is 'doomed', firms will not go there and its skilled young will leave. One role of public policy in achieving spatial balance of opportunities is to anchor expectations through an irreversible commitment such as the provision of economic infrastructure and thereby a shift in such narratives.

\section{Lessons from Britain and Germany}

Britain's spatial distribution of economic activity is an extreme example of the consequence of market forces allied to a conviction narrative that has favoured London, with no attempt to use offsetting public policies. The Gini Coefficient of spatial activity in Britain is far higher than any other large country in Europe.

Some market fundamentalists believe that such extreme agglomeration is allocatively efficient: people in London are highly productive, especially the skilled, and so concentrating more skilled people in London would be even more efficient. The fallacy in this is that extreme concentrations of people in megacities result in a loss of liveability. Although London is efficient at transforming inputs into income, it is highly inefficient at transforming income into well-being. Although London is the region with the highest average income in Britain, it is also the region with the lowest average score on 'well-being'. The reasons for this are not yet adequately analysed, but both the material conditions of congestion reflected in crowded commuting and lack of floor space, and the social isolation reflected in a loss of proximity to family and belonging to community, are plausible contenders. Further, the same spatial narrative that supported the success of London, namely, that it was the place to go for bright young people, deepens the demoralisation of the people remaining in regions that are being left behind.

That public policy, sustained over decades, can achieve a wide spatial distribution of successful cities is demonstrated by Western Germany. After two decades of active policy and massive fiscal transfers, Eastern Germany has achieved considerable convergence of incomes, but that has been insufficient to prevent the emergence of grievance over 'second-class citizenship'. In Britain, the only city apart from London that has productivity above the national average is Edinburgh. The comparison of Edinburgh with the successful dispersion of knowledgeclusters in West and limited successes in East Germany, may help to guide spatial policies in the larger context of Europe. While we still do not fully understand how to catalyse successful cities, a combination of seven characteristics looks to be helpful. 
The first characteristic is local political autonomy. Edinburgh, like German cities, has considerable developed political power. In Germany, this is an implication of the federal constitution, in Britain it is a consequence of the rise of Scottish nationalism (itself a consequence of the location of Britain's oilfields).

The second characteristic is a locally based finance industry. Only if finance is locally based can it use the tacit knowledge in lending decisions that comes from frequent personal contact with the management of local firms. Further, only locally based finance has an overarching alignment of long-term purpose regarding local prosperity. The finance industry always starts as local, because of the value of local knowledge for lending decisions, but the dangers posed by spatially correlated default risks create a centripetal force. By the end of the 19th century, the Bank of England had forced the pooling of spatial risks by requiring the merger of the many regional banks into just five national banks, all of which were London-based: outside London, Britain has very few financial centres. Edinburgh is an exception because Scottish law is distinct from English law, and the remit of the Bank of England did not extend there. The German central bank solved the risk problem by insurance rather than concentration, so that German banking remained local.

The third characteristic is a locally organised business community. This is probably consequential on the first two characteristics: for obvious reasons, business communities tend to organise themselves so as to be near to political and financial decision-taking. In Edinburgh and most German cities that is local, while in England it is national, and clustered in London. In Germany, public policy has considerably encouraged the local basis for business organisation by legislation which gives such organisations important functions.

The fourth characteristic is locally based institutions of tertiary education. Their potential importance to the local economy is partly for training in locally pertinent skills, and partly to generate research that helps to keep knowledge-intensive firms sufficiently close to the frontier that they can sustain their position. Again, legislation can help or impede links between education and local business. For example, in the 1980s Britain converted its locally oriented technical colleges - 'Polytechnics' - into universities, and this changed their sources of finance, reducing their links to local government and local business. In contrast, the Scottish Government has strengthened the local connections of its universities: uniquely in Britain, it has made its universities free to students - but only if they are Scottish. German tertiary education has far stronger links with local business, through its prestigious vocational training programs.

The fifth characteristic is a civic society that generates a strong sense of local culture: civic society in Edinburgh pioneered the city's annual festival, which has created a 'brand' attracting 500,000 people from around the world. German cities have particularly strong civic society, partly because public policy encourages participation in verein which have considerably expanded.

The sixth characteristic is an infusion of public finance that empowers local political leadership to upgrade the infrastructure that can anchor a new narrative, and which can be used to encourage the other local actors to collaborate. Edinburgh was fortunate to benefit financially from the political consequences both of Scotland's oil, and of a Scottish-dominated government for the period 1997-2010, which between them sustained a large fiscal transfer to the Edinburgh-based Scottish Government. Public spending in Scotland has been approximately $15 \%$ higher than that in England.

The seventh and final characteristic is good local leadership that forges purposive collaboration between local government, local business, local colleges and local civic society. The purpose must be feasible, forward-looking and seen as beneficial to all, so that it can be held in common. In the absence of such leadership, the more likely outcome in a broken city is that the narrative of local prospects becomes discordant and backward-looking, as each entity blames the others for failure, an example being enmity between the local government and local business. In Edinburgh in 2009, leaders brought the various local entities together to agree on attracting a sector that had the potential to generate knowledge-intensive jobs: they chose information technology. At the time, the city had only two such firms, but with each entity playing its role, Edinburgh was able to attract many more. As of 2019, Edinburgh had 480 IT firms - the largest cluster in the whole of Europe. Again, public policy can help or hinder the emergence of good local leadership. Germany has long had powerful mayors. Being a clear route to the top of national politics, these positions attract highly able people: for example, Germany's current Minister of Finance and Deputy Chancellor was previously the Mayor of Hamburg. In contrast, other than in London, England is only now piloting the idea of mayors.

Not only can these characteristics account for the success of Edinburgh and the cities of West Germany, their absence may help to explain both why Britain has greater spatial inequality than Germany, and why, although East Germany has caught up in terms of incomes, its popu- 
lation has become highly disaffected. East Germany did not start in 1990 with local business communities: its state enterprises were nationally organised. The massive financial transfers were primarily to raise per capita consumption and to attract subsidiary operations of West German businesses rather than to build prosperous local businesses. Hence, East Germany has been slow to develop locally rooted business communities. Further, the GDR system of top-down mass scrutiny had undermined local social cohesion and cooperation: people had become distrustful of each other and had little experience with local collective initiative. The national policies implemented in post-1990 East Germany have consequently not enabled its cities to build the interdependent clusters of knowledge-intensive firms which would have retained bright young people. Instead, its cities have filled up with the low-cost, low-skill enterprises predicted by Venables. ${ }^{11}$ Consumption levels have risen, but have stalled at significantly below West German levels.

\section{Implications for European policy}

The internal market will not automatically induce spatial convergence. While it is not feasible to bring productive jobs to wherever people want to live, a reasonable goal is to ensure that every region of Europe has at least one city that has a knowledge-intensive cluster of businesses that are competitive either globally, or at least within the European market. Good regional transport infrastructure would then enable people who belong to the region's other towns and cities to remain in them, some commuting, and the rest working in activities openerating in more localised markets. West Germany suggests that such a spatial distribution could be self-sustaining; Edinburgh suggests that it is feasible to catalyse successful cities; and East Germany suggests that it will take more than fiscal transfers: most of the remaining six desiderata were missing.

The appropriate role for the Commission is to orchestrate, region-by-region, the provision of the seven characteristics that appear to be effective in catalysing a successful city. Evidently, this cannot mean that the Commission itself directly provides them, but that it works with national and regional governments to ensure that there is a coherent plan within which public actions are clearly assigned. The Commission already has a Structural Fund. Were this fund linked to the purpose of catalysing a successful city in each region, money for a city could be made conditional upon the other levels of government - national, regional and municipal - each playing its appropriate role in contributing to specific parts of the seven-characteristic

11 A.S. Venables, op. cit. package. Evidently, the larger the fund, the more leverage it would provide.

\section{Reversing skill divergence}

Skill accumulation must necessarily occur through two distinct paths. Universities deepen the abilities of those young adults well-suited to cognitively focused education, and this provides a cognitive platform on which specialist professional skills can be built. This process is generally working well in Europe, with Britain being the most successful. The half of young adults whose abilities are less suited to cognitively focused education need to make a more demanding transition to the acquisition of a range of non-cognitive, vocational skills. This process varies considerably around Europe. In many countries this group is falling further behind those with cognitive abilities, with Britain being among the least successful. ${ }^{12}$

Fortunately, the diverse range of policies important for non-cognitive skill accumulation around Europe provides a natural arena for rapid social learning. The process, which results in a young adult who is fully equipped with the necessary non-cognitive skills to be productive and then maintains them, consists of a long chain of distinct phases, each dependent upon specific supportive public policies. Although no country has a complete chain of such policies that are best-practice, for each phase some European country can reasonably be judged successful. The role of the Commission is not to force standardisation of these policies, but to encourage more rapid learning from this variation. Through comparison, evaluation, and persistent emphasis, rapid and substantial improvements in addressing skill divergence could be achieved.

Non-cognitive capacities are forged right from conception. A recent Finnish study that tracked the consequences of stress in pregnancy for forty years found that the damage to personality was substantial and highly persistent. ${ }^{13}$ It is likely to be more effective to focus policy on reducing stress in pregnancy than in coping with its consequences. More generally, during the period from conception to the age of around three years, the priority seems to be to support young mothers and strengthen their families. An example of such practical support in the home is the Dutch policy of providing home help to mothers facing demanding situations. In contrast, the British

12 J.Blanden, S. McNally, G. Wyness: Election Analysis, Centre for Economic Performance, London School of Economics, 2019.

13 R. Brannigan, A. Tanskanen, M. Huttunen, M. Cannon, F. Leacy, M. Clarke: The role of prenatal stress as a pathway to personality disorder: Longitudinal birth cohort study, in: The British Journal of Psychiatry, 6 September 2019, pp. 1-5. 
social work system is designed around scrutiny of parents under threat of child-removal: ${ }^{14} 70,000$ children are currently being reared in foster care, which being temporary and paid, struggles to provide the secure, loving environment that young children need.

From the age of two to five, non-cognitive capacities can be enhanced by socialisation. A good model is the French pre-school system of ecoles maternelles. One strength of this system is that it is free and standardised, so that attendance has become the social norm. Hence, there is no stigma attached to it, so that the children who are most in need of it are very likely to be sent by their parents. Because provision is by means of formal entities, with a headmistress and professionally qualified staff, children get a structured learning experience where their progress can be monitored. Additionally, being a full fledged organisation, it can readily catalyse a community among parents, reducing the stress of isolation.

By the age of six, the cognitive performance of the child when aged 12 can be accurately predicted. While the years of schooling receive enormous policy attention, Putnam argues convincingly that schools are predominantly sites at which children interact with each other, thereby reinforcing whatever characteristics children have acquired in their homes. ${ }^{15}$ Assortative mating, followed by assortative location, leaves schools little scope for redressing weaknesses. Again, an implication is that resources should be focused on the first six years. There are, however, substantial variations around Europe in school practices, with Finland recognised as having among the most successful outcomes.

Post-school, there are wide variations in the provision of vocational training. One lesson from failures in vocational training is that local firms need to be fully involved in the design and execution of training. ${ }^{16}$ Another is that to achieve a high level of skill, and the ability to acquire related skills, courses need to be long - typically three to four years - and properly accredited. A particularly successful model is Switzerland, where $60 \%$ of schoolleavers choose to take the vocational route. Firms have a strong incentive to be involved because they finance half of the costs.

Finally, given rapid changes in the demand for skills, many people will need to change their vocations. Train-

14 H. Cottam: Radical Help, London 2018, Little Brown.

15 R. Putnam: Our Kids, an American Dream in Crisis, New York 2016, Simon and Schuster.

16 A. Goldstein: Janesville: an American Story, New York 2018, Simon and Schuster. ing courses will need to cater to older workers, and the public finance of skill acquisition needs to be structured for lifetime learning. For example, the French government has introduced a lifetime training entitlement of 5,000 euro. A related proposal by Jean Tirole is that a firm that makes workers redundant should bear the costs to society of retraining, so that it would have a stronger incentive to keep its workforce sufficiently skilled to remain productive. ${ }^{17}$

\section{Conclusion}

Europe, like other advanced economies, has faced social pressures arising from the globalisation of markets and the increasing complexity of production. However, the European Commission has been given competences and implemented policies which, while they have increased overall productivity, have sometimes compounded these social pressures. The Commission has lacked the competences that would have equipped it to address the understandable anxieties of those at the wrong end of these pressures. Perhaps in consequence, support for Europe is strongest among the winners from globalisation and the rise in complexity, and lowest among those who feel threated. As an extreme but perhaps justifiable simplification, the Commission draws its support base from well-educated metropolitans, whereas its opponents are provincial manual workers.

To the extent that this is the case, it is a substantial weakness. Centralised European authority must rest, at least in part, upon a sense of common identity in which the successful accept that they have obligations to the less successful, and thereby commit to a Europe of convergence. Convergence cannot just be about consumption: people want the empowerment, the agency that comes from being sufficiently productive to be able to contribute to society, rather than being a burden on it. Hence, convergence is about productivity: poor regions must become more productive relative to richer regions, and less skilled people must become more productive relative to the most skilled. This convergence of productivity across Europe's regions and classes - analogous to what happened within most European countries during the period 1945-70 - is the challenge for the Commission in the 2020s. It is a feasible goal, but clearly not one that the Commission can achieve purely through its own competences. Rather, the Commission needs to equip itself to orchestrate policies that will largely be the responsibility of national, regional and municipal governments.

17 See the discussion of the proposal in P. Collier, op. cit., p. 177. 